\title{
Clinical prognosis and gene expression profiles of prostate cancer patients with bone and lymphatic metastases
}

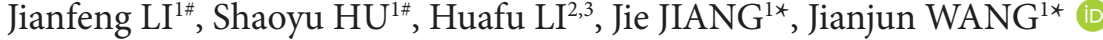

\begin{abstract}
In this paper, we aimed to observe the prognosis and gene expression profiles of bone and lymphatic metastases. SEER ${ }^{\star}$ Stat software was used to collect prognosis analysis. Datasets of gene expression profiles were downloaded from the GEO database. GEO2R tool was used to analyze the data to identify the differentially expressed genes (DEGs). Functions of DEGs were annotated by KEGG. Protein interaction analysis and hub gene selection were performed using STRING database. The overall survival rate (OS) of Lymph node metastasis was better than that of bone metastases. In lymph node metastasis prostate cancer, the expression of ZWINT, DNMT3B and RAD54B was higher than that in bone metastasis prostate cancer; the expression of HBA2, MS4A4A, COLCE, CCL18, DCN, S100A4, ACP5, ARHGDIA, MEM204, GALR3, CTSZ, and EPHX1 was lower than that in bone metastasis prostate cancer. DEGs in bone metastasis prostate cancer were involved in various biological processes, such us enhancing the adhesion and chemotaxis, immune correlation and promoting malignant transformation of cancer cells. The data suggests that gene expression patterns of these two profiles are different. Bone metastasis may be poor prognosis and higher malignancy.
\end{abstract}

Keywords: bone metastasis; prostate cancer; lymphatic metastasis; gene expression profiles.

Practical Application: We used bioinformatics tools to analyze the gene expression changes of bone metastasis and lymph node metastasis in prostate cancer.

\section{Introduction}

Prostate cancer is the highest incidence of men in the world, with about 90 million new cases each year. The incidence of prostate cancer is very different around the regions, with the highest incidence in western developed countries and the lowest in Asian countries (Pernar et al., 2018). Prostate cancer mortality is a low risk in screening population. In the United States, one of 7 people is diagnosed with prostate cancer in his lifetime, and only $1 / 30$ of them die from prostate cancer. According to the survey, the 5 year survival rate of patients diagnosed with prostate cancer from 2005 to 2011 is $98.9 \%$ (Brawley, 2012). The low mortality rate of prostate is mainly due to slow growth of prostate cancer and early detection of prostate-specific antigen (PSA) (Moul et al., 2002). Early radical prostatectomy can significantly improve the prognosis of patients (Torre et al., 2015). However, in some Asian countries, such as China, most of the prostate cancer patients are in the middle and late stages of the first diagnosis, and they can only accept palliative treatment based on androgen blockade. These patients have poor prognosis (Etzioni et al., 2008). The most common metastatic sites of prostate cancer are lymph node metastasis and bone metastasis. The autopsy report found $80 \%$ prostate cancer will develop bone metastasis (Huang et al., 2006). The mortality of prostate cancer patients with bone metastasis is significantly higher than that of patients without bone metastasis. The risk of bone metastasis is even greater than that of prostate cancer itself (Mundy, 2002). Operating prostate cancer increased the incidence of lymph node metastasis to $40 \%$ (Swanson et al., 2006). Lymph node metastasis significantly affects the prognosis of patients with prostate cancer (Arai et al., 1998). When adenocarcinoma cells are colonized in the bone marrow, some growth factors are produced. These factors stimulate the matrix to produce blood vessels, form tumor microenvironment and facilitate the growth of tumor cells (Ohta et al., 2002; Hu et al., 2021; Khan et al., 2021; Balthazar et al., 2021). Tumor colonization is due to some special bone marrow tumor cell factors. For lymph node metastasis and metastasis, it is found that the gene expression products of bone metastasis and lymphatic metastasis are different. Bone metastasis can increase the expression of IBSP (Bone sialoprotein) and F13A1 (factor XIII) and reduce EFNA1 (ephrin-A1) and ANGPT2 (ephrin-A1) and ANGPT2 than lymph node metastasis. The expression of these genes will affect the metastasis of tumor cells (Morrissey et al., 2008).

These studies show that the mechanisms of bone and lymph node metastases are different. However, the effects of bone and lymph node metastasis on the prognosis of patients and gene expression are still unknown. In this paper, we aimed to find the 
evidence of the prognosis and gene differential expression of the bone metastasis and lymph node metastasis of prostate cancer from the perspective of large data. We carried out data mining analysis through the large data of Surveillance (Epidemiology, and End Results, SEER), the database of human tumor related gene expression assembler (Gene Expression Omnibus, GEO), through the large tumor registration database of the National Cancer Institute of the United States. We hope that our study will facilitate the accurate clinical treatment.

\section{Database and patient selection}

\subsection{Research object of prognosis analysis}

$\mathrm{SEER}^{\star}$ Stat software was used to collect patients who underwent radical prostatectomy and non operative treatment from 2004 to 2013 in SEER database. According to the patient's marital status, age, race, T staging and pathological staging were grouped by random number table method. They were divided into operation bone metastasis group, operation lymph node metastasis group, nonoperative bone metastasis group and nonsurgical lymph node metastasis group. A total of 2632 patients were included in this study. The shortest follow-up period is 1 month, the longest is 200 months. Among them, 129 cases had surgical bone metastases, with an average age of (62.42 \pm 6.82$)$ years. Surgical lymph node metastasis in 131 cases, the average age of patients was $(61.69 \pm 7.04)$ years. Non-operative bone metastasis group in 1260 cases, the average age of patients was $(65.95 \pm 9.19)$ years. Operation alone lymph node metastasis group in 1260 cases, the average age of patients was $(66.60 \pm 8.95)$ years. Patient characteristics are listed in Table 1.

\subsection{Research object of gene difference analysis}

Gene expression data come from the comprehensive database of gene expression (http://www. ncbi. nlm. nih. gov/geo/), the material is radical prostatectomies, and separate tumor cells after operation. The Agilent $44 \mathrm{~K}$ whole human genome expression oligo nucleotide microarrays method was sequenced by Agilent Technologies. The GEO landing number is GSE74367 (Roudier et al., 2016). It was submitted by Ilsa Coleman, including 7 patients with prostate cancer and 19 patients with lymph node metastasis from prostate cancer.

\section{Statistical analysis}

\subsection{Prognostic statistical analysis}

The OS was calculated by Kaplan-Meier method, and the difference of OS was compared with Log-Rank method. The above statistics are analyzed by SPSS18.0 software. Frequency distribution of demographic and clinicopathological characteristics across metastatic groups were compared using Pearson's chisquare tests.

\subsection{Differential expression gene analysis}

The GEO2R online analysis tool of GEO database was used to analyze differentially expressed genes (http://www. ncbi.

Table 1. Baseline characteristics.

\begin{tabular}{|c|c|c|c|c|c|c|}
\hline \multirow[b]{2}{*}{ Characteristic } & \multicolumn{2}{|c|}{ Radical prostatectomy } & \multirow[b]{2}{*}{$\mathrm{P}$} & \multicolumn{2}{|c|}{ Non-Radical prostatectomy } & \multirow[b]{2}{*}{$\mathrm{P}$} \\
\hline & Bone $(n=129)$ & $\begin{array}{c}\text { Lymphatic } \\
(\mathrm{n}=131)\end{array}$ & & Bone $(n=1260)$ & $\begin{array}{l}\text { Lymphatic } \\
(\mathrm{n}=1112)\end{array}$ & \\
\hline Mean age $(\mathrm{X} \pm \mathrm{s})$ & $62.42 \pm 6.82$ & $61.69 \pm 7.04$ & 0.401 & $65.95 \pm 9.19$ & $66.60 \pm 8.95$ & 0.08 \\
\hline \multicolumn{7}{|l|}{ Race, no. (\%) } \\
\hline White & $97(75.13 \%)$ & $94(71.76 \%)$ & 0.746 & $887(70.40 \%)$ & $817(73.47 \%)$ & 0.117 \\
\hline African American & $20(15.50 \%)$ & $25(19.08 \%)$ & & $274(21.75 \%)$ & $208(18.70 \%)$ & \\
\hline Other & $12(9.37 \%)$ & $12(9.16 \%)$ & & $99(7.86 \%)$ & $87(7.83 \%)$ & \\
\hline \multicolumn{7}{|l|}{ Marital status, no. (\%) } \\
\hline Single/widowed/divorced & $23(17.83 \%)$ & $30(22.90 \%)$ & 0.547 & $351(27.86 \%)$ & $321(28.87 \%)$ & 0.822 \\
\hline Married & $97(75.19 \%)$ & $94(71.76 \%)$ & & $838(66.51 \%)$ & $726(65.29 \%)$ & \\
\hline Unknown & $9(6.98 \%)$ & $7(5.34 \%)$ & & $71(5.63 \%)$ & $65(5.85 \%)$ & \\
\hline \multicolumn{7}{|l|}{ AJCC T stage, no. (\%) } \\
\hline $\mathrm{T} 1 \mathrm{c}$ & $3(2.33 \%)$ & $1(0.76 \%)$ & 0.983 & $655(51.98 \%)$ & $538(48.38 \%)$ & 0.263 \\
\hline $\mathrm{T} 2 \mathrm{a}$ & $12(9.30 \%)$ & $12(9.16 \%)$ & & $24(1.90 \%)$ & $24(2.16 \%)$ & \\
\hline $\mathrm{T} 2 \mathrm{~b}$ & $4(3.10 \%)$ & $4(3.05 \%)$ & & $32(2.54 \%)$ & $34(3.06 \%)$ & \\
\hline $\mathrm{T} 2 \mathrm{c}$ & $48(37.21 \%)$ & $50(18.17 \%)$ & & $183(14.52 \%)$ & $176(15.83 \%)$ & \\
\hline $\mathrm{T} 3 \mathrm{a}$ & $34(26.36 \%)$ & $35(26.72 \%)$ & & $69(5.48 \%)$ & $67(6.03 \%)$ & \\
\hline $\mathrm{T} 3 \mathrm{~b}$ & $21(16.28 \%)$ & $22(16.79 \%)$ & & $112(8.89 \%)$ & $126(11.33 \%)$ & \\
\hline $\mathrm{T} 4$ & $7(5.42 \%)$ & $7(5.34 \%)$ & & $185(14.68 \%)$ & $147(13.22 \%)$ & \\
\hline \multicolumn{7}{|l|}{ pathological staging,no. (\%) } \\
\hline Well differentiated & $2(1.55 \%)$ & $1(0.76 \%)$ & 0.862 & $0(1.55 \%)$ & $1(0.76 \%)$ & 0.724 \\
\hline Moderately differentiated & $26(20.16 \%)$ & $28(21.37 \%)$ & & $70(20.16 \%)$ & $63(21.37 \%)$ & \\
\hline Poorly differentiated & $99(76.74 \%)$ & $101(77.11 \%)$ & & $1179(76.74 \%)$ & $1040(77.11 \%)$ & \\
\hline Undifferentiated & $2(1.55 \%)$ & $1(0.76 \%)$ & & $11(1.55 \%)$ & $8(0.76 \%)$ & \\
\hline EBRT received, no. (\%) & 0 & 0 & & 0 & 0 & \\
\hline Beam radiation received, no. (\%) & 0 & 0 & & 0 & 0 & \\
\hline
\end{tabular}


nlm. nih. gov/geo/geo2r/). GEO2R is based on R programming language, using $\mathrm{R}$ and GEO query and limma package, and $\mathrm{t}$ test to screen differentially expressed genes (Huber et al., 2015). Gene expression profiles have high dimensions (the number of genes are very high, usually thousands or even tens of thousands) and small sample size, and multiple hypothesis testing (Multiple test) control is needed. In this study, multiple hypothesis test control uses the false positive rate control method proposed by Benjamini and Hochberg (Ge et al., 2009). The screening standard of differential genes was $P<0.01$, corrected $P$ value (adjusted $P$-value) $<0.01$, and gene expression value varied (Fold change, FC), which was more than 2. Display through thermal imaging method.

The functional annotation and pathway analysis of differentially expressed genes are annotated by KEGG (Kanehisa et al., 2010). A statistical method of improved Fisher accurate test was used to analyze whether the differentially expressed genes appeared on a functional node, and a significant association of gene function classes or pathways was obtained, and the functional classes were output according to their $P$ values. $P<0.05$, multiple test corrected $P$ value $<0.05$, and the number of genes enriched to count $>2$ was statistically significant. Differentially expressed gene core proteins screening and utilizing an interactive gene retrieval tool (the Search Tool for the Retrieval of Interacting Genes, STRING, http://string-db.org/) protein interaction database (Franceschini et al., 2013). The interaction between the proteins encoded by differentially expressed genes in the prostate cancer tissue was analyzed, and the Protein protein interaction (PPI) was constructed. The interaction score combination score $>0.4$ was the threshold condition for the existence of interaction. Import the interactive data from STRING into Cytoscape software (Shannon et al., 2003). The size of the gene circle represents the impact fraction of the gene, and the size of the action is Interaction size that indicates that the protein that affects the fraction of the larger fraction is the core protein (gene) with important physiological function.

\section{Result}

\subsection{Survival analysis}

At 1, 3, 5 years after operation, OS was $92.6 \%, 88.9 \%$, and $75.9 \%$ in the operation group, and the patients with lymph node metastases in the operation group were $97.6 \%, 94.6 \%, 92.2 \%$, separately. The difference of OS between the two groups was statistically significant $(P=0.002)$, and lymph node metastasis OS was better than that of bone metastases (Figure 1). The OS of 1,3 , and 5 years in non operative group was $83.2 \%, 50 \%, 32.4 \%$, and the patients with lymph node metastasis in non operative group were $94.8 \%, 78.9 \%, 63.8 \%$, separately. The difference between the two groups of patients with OS was statistically significant $(P<0.001)$, Lymph node metastasis OS is superior to bone metastases (Figure 2).

\subsection{Differentially expressed genes}

Up to 54 genes were differentially expressed in lymph node metastasis and bone metastasis prostate cancer, and 160 down regulated genes were shown in Figure 3 and Figure 4. The top ten up-regulated genes were SCN2A, PEG10, LOC344593, IPW, SLC29A4, TGM3, TFRC, APCS, SLC6A17 and SERPINA6. The top ten down-regulated genes were PLA2G2A, SPP1, NEFH, CRISP2, COL11A1, SCUBE2, ACPT, HBA2, CAMK2N1 and CXCL14.

\subsection{Biological function annotation and signal transduction analysis of differentially expressed genes}

The KEGG functional annotation showed that the genes of bone metastases in prostate cancer were up regulated in 13 Biological process, $\mathrm{BP}$, and ordered by $\mathrm{P}$ (Figure 5). It mainly involves systemic lupus erythematosus, Huntington's disease, allograft rejection, artine's disease, reabsorption of water, Parkinson's disease, prion disease, amyotrophic lateral sclerosis,

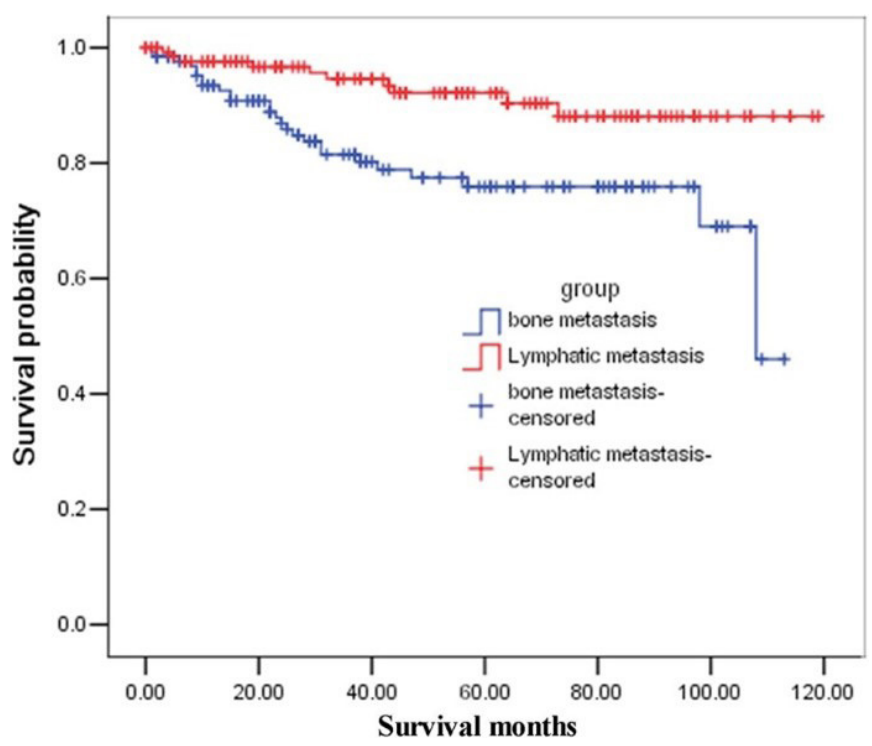

Figure 1. Kaplan-Meier graphs of survival in months of patients with radical prostatectomy.

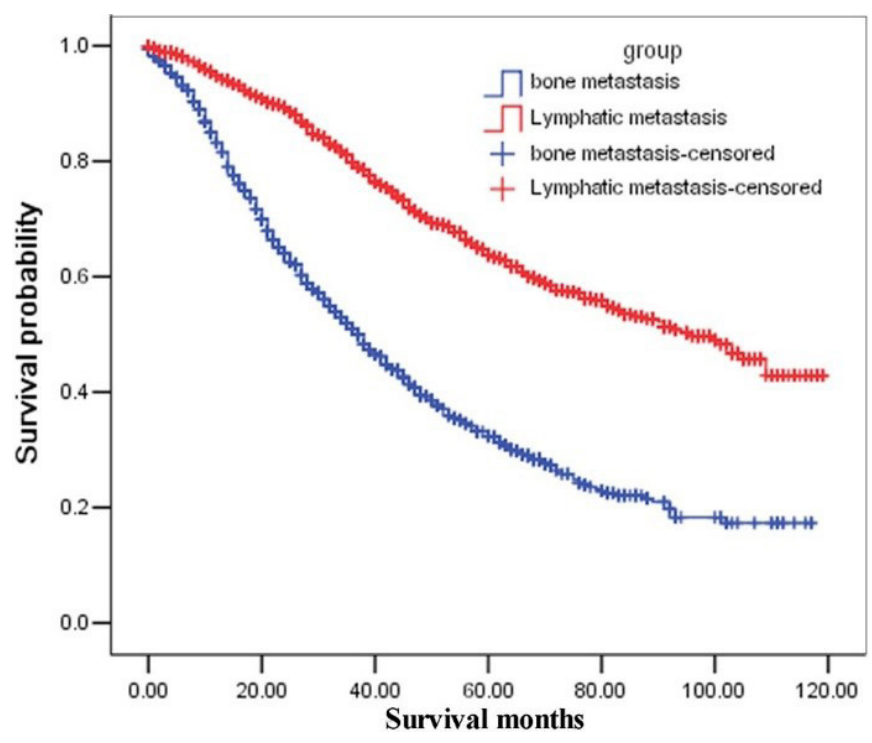

Figure 2. Kaplan-Meier graphs of survival in months of patients with non-radical prostatectomy. 


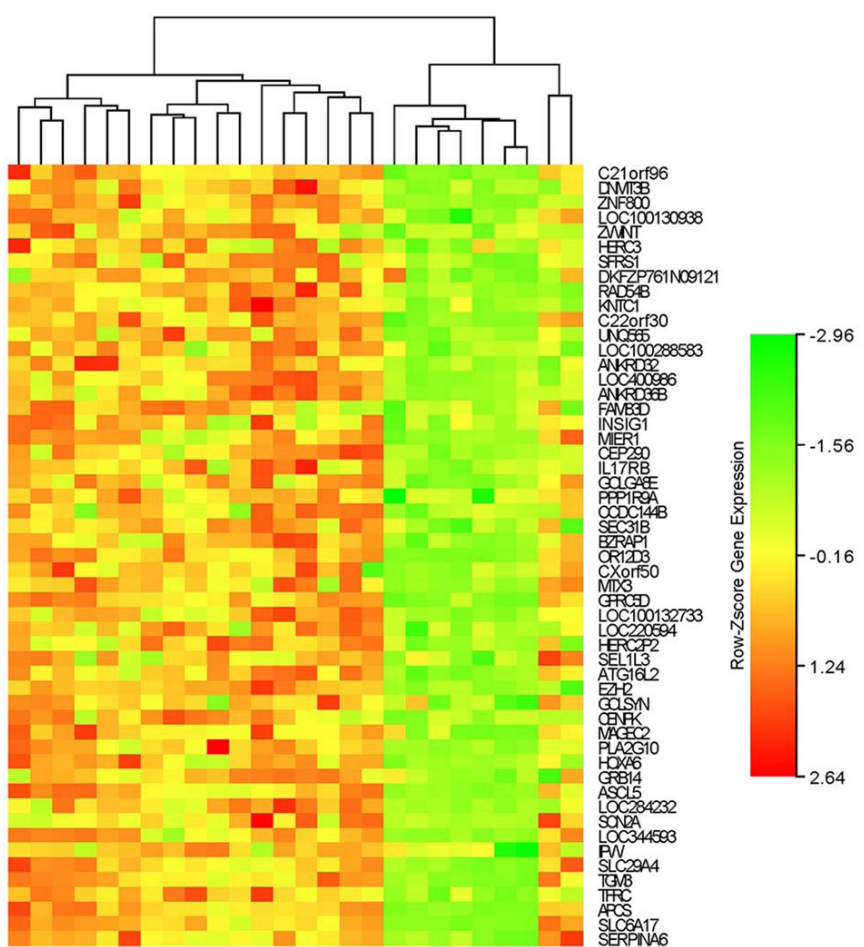

Figure 3. Up to 54 genes were differentially expressed in lymph node metastasis and bone metastasis prostate cancer.

adhesion, neurotrophic factor signaling, renal cell carcinoma, alanine, and glutamic acid metabolism. There was no significant accumulation of genes with differential expression in lymph node metastasis.

\subsection{Screening of key genes differentially expressed in prostate cancer tissures}

Lymph node metastasis prostate cancer contrasts with bone metastasis prostate cancer differentially expressed genes up to 54 genes to construct a protein interaction network to remove isolated and non interacted protein nodes. Eight proteins have interaction relationships. The size of the gene circle represents the impact fraction of the gene, the size of which is represented by the size of interaction. According to Figure 6, ZWINT, DNMT3B and RAD54B play important roles. In the differentially expressed genes of bone metastasis and lymph node metastasis, 160 genes are down-regulated to construct a protein interaction network, removing isolated and non interacted protein nodes, and screening out the interaction relationship between the 90 genes encoded by the genes. The size of the gene circle represents the impact fraction of the gene, and the size of the action is expressed in the size of interaction. According to Figure 7, HBA2, MS4A4A, COLCE, CCL18, DCN, S100A4, ACP5, ARHGDIA, MEM204, GALR3, CTSZ, EPHX1 play important roles.

\section{Discussion}

Bone is the most common metastatic site of prostate cancer. Bone metastasis occurs in $90 \%$ of prostate cancer cases (Lu et al., 2007). About 350000-400000 prostate cancer patients die from

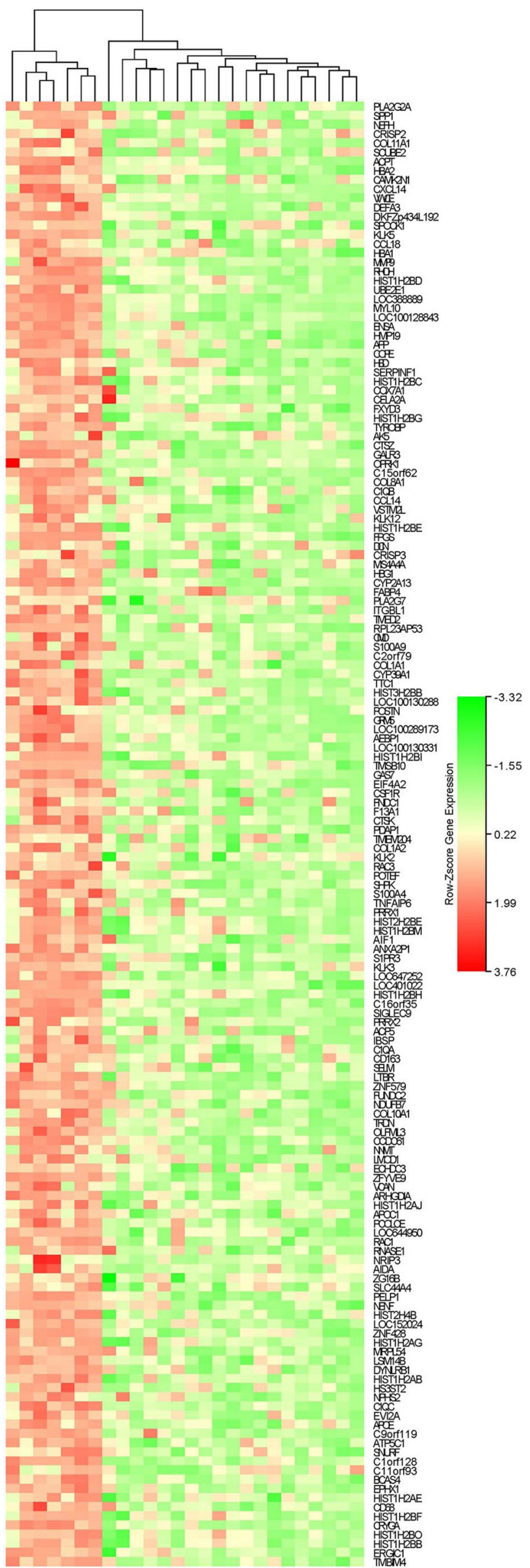

Figure 4. 160 down regulated genes were differentially expressed in lymph node metastasis and bone metastasis prostate cancer. 
A

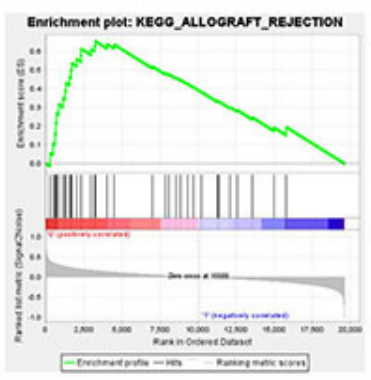

E

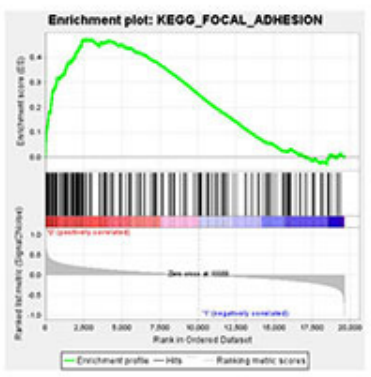

I

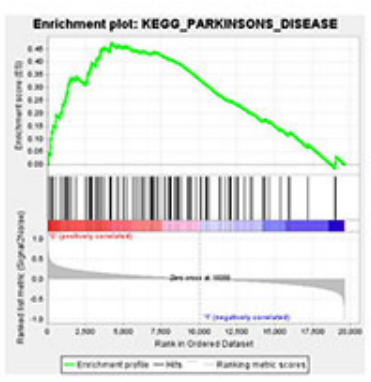

B

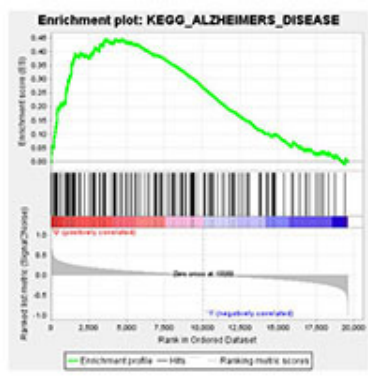

$\mathbf{F}$

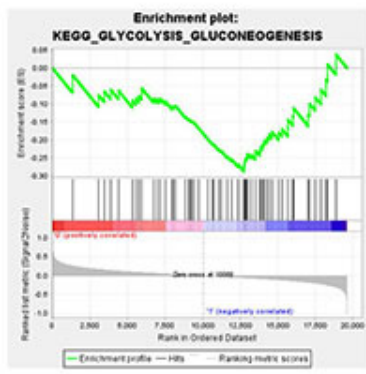

J

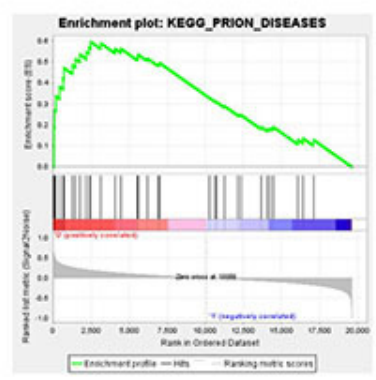

C

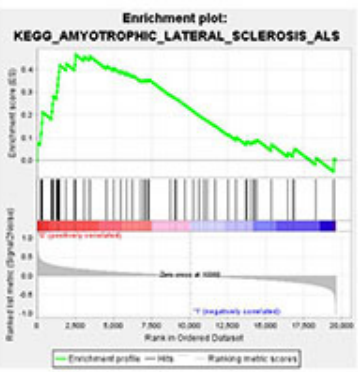

$\mathbf{G}$

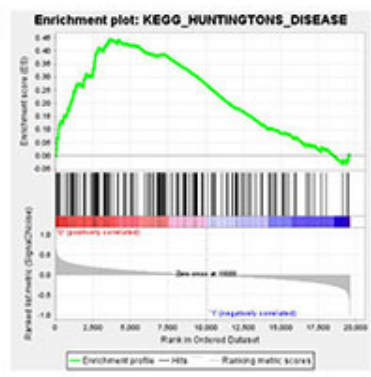

K

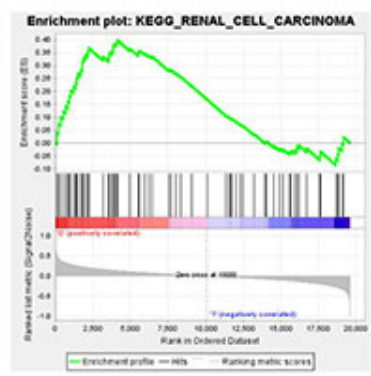

D

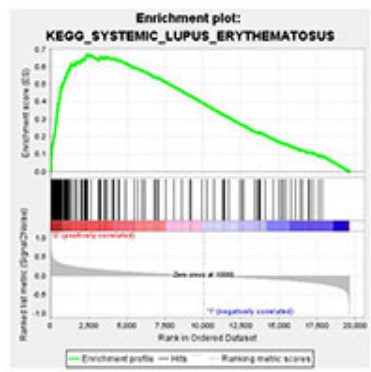

H

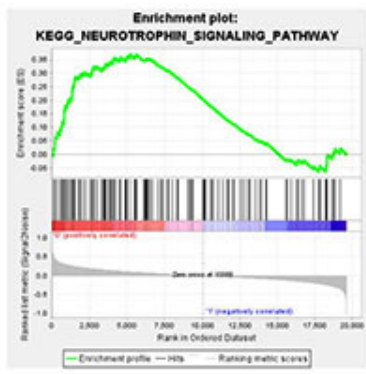

$\mathbf{L}$

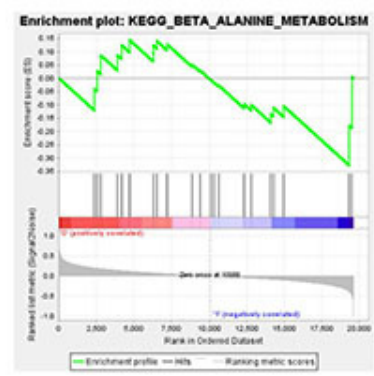

\section{M}

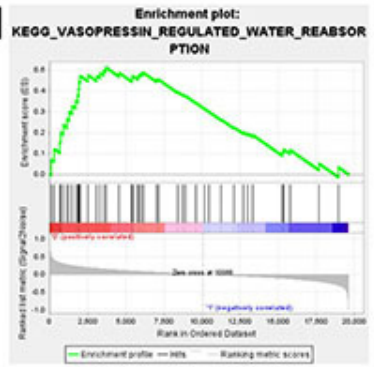

Figure 5. The KEGG functional annotation showed that the genes of bone metastases in prostate cancer.

bone metastases every year (Roodman, 2004). Bone metastases lead to serious complications, such as pain, impaired bed mobility, pathological fracture, spinal cord compression and hypercalcemia (Coleman, 1997). The neoplastic lymphatic vessels and vessels are morphological basis for their metastasis, and some data indicate that among the confirmed prostate cancer patients, the number of lymph node metastases is $41 \%$, of which $70 \%$ patients died (Stacker et al., 2001). The study of bone metastasis related signaling pathway in prostate cancer shows that bone metastasis is mainly related to the MET gene and the vascular endothelial growth factor (VEGF) pathway (Lee et al., 2014), beta 2- adrenoceptor (beta 2-adrenergic receptor, ADRB2) signaling pathway (Braadland et al., 2015), androgen receptor pathway (Chen et al., 2017) and signaling pathway (Mizutani \& Pienta, 2008). The genes related to the signaling pathways associated with lymph node metastasis in prostate cancer and the pathway are VEGF pathway (Hirakawa et al., 2005), ERG related fusion gene (Huang et al., 2016a), cathepsin and matrix metalloproteinase (MMP) gene (Tian et al., 2014), and so on. By comparing the prognosis of simple prostate cancer patients with bone metastasis and simple lymph node metastasis, it is found that the prognosis of lymph node metastasis of prostate cancer is better. The number of differential expressed genes of the lymph node metastasis and the bone metastasis was 54, of 
which 8 genes were interrelated, and the ZWINT, DNMT3B and RAD54B genes were the major up-regulated genes. The number of down regulated differential expressed genes was 160, of which 90 down regulated proteins are interacted. The main differentially regulated genes are HBA2, MS4A4A, COLCE, CCL18, DCN, S100A4, ACP5, ARHGDIA, MEM204, GALR3, and CTSZ.

Bone metastasis of prostate cancer caused HBA2, MS4A4A, COLCE, CCL18, DCN, S100A4, ACP5, ARHGDIA, MEM204,

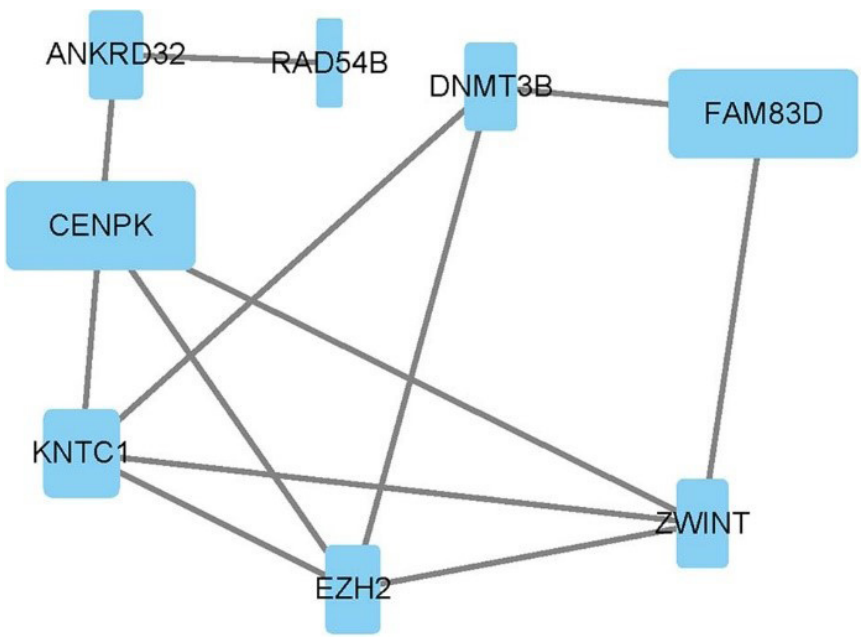

Figure 6. Differentially up-regulated key genes expressed in prostate cancer tissues.
GALR3, CTSZ, EPHX1,MYL10, ZNF579 and other genes up regulation. It also affects the biological processes related to systemic lupus erythematosus, Huntington's disease, allograft rejection, auriculotin's disease, reabsorption of water, Parkinson's disease, prion disease, amyotrophic lateral sclerosis, adhesion, neurotrophic factor signaling, renal cell carcinoma, alanine, and glutamic acid metabolism. The effects of these genes on the prognosis of bone metastases mainly include enhancing the adhesion and chemotaxis, immune correlation and promoting malignant transformation of cancer cells. The DCN gene (decorin) significantly increased the expression level of $\mathrm{E}$ - cadherin and inhibited the migration and invasion function of tumor cells (Bi et al., 2012). CCLl8, also known as macrophage inflammatory protein-4 (MIP-4), is a chemokines, mainly secreted by M2 macrophages, which can enhance the invasiveness and metastasis of tumors (Chen et al., 2011). SlooA4 protein is an important factor which is closely related to the invasion and metastasis of malignant tumor, which is closely related to the invasion and metastasis of malignant tumor. It participates in many physiological processes, such as cell adhesion and separation, extracellular matrix reconstruction, cell movement, angiogenesis and so on (Mazzucchelli, 2002). ARHGDIA gene encodes the Rho GDP dissociation inhibiting factor alpha, which inhibits the occurrence of lymph node metastasis (Shida et al., 2013). The expression of CTSZ plays an important role in the proliferation, invasion and metastasis of tumor cells. When the expression of CTSZ gene in the tumor cells is increased, the expression of the cell marker (vimentin) is increased, the expression of the epidermal cell marker (calcin,

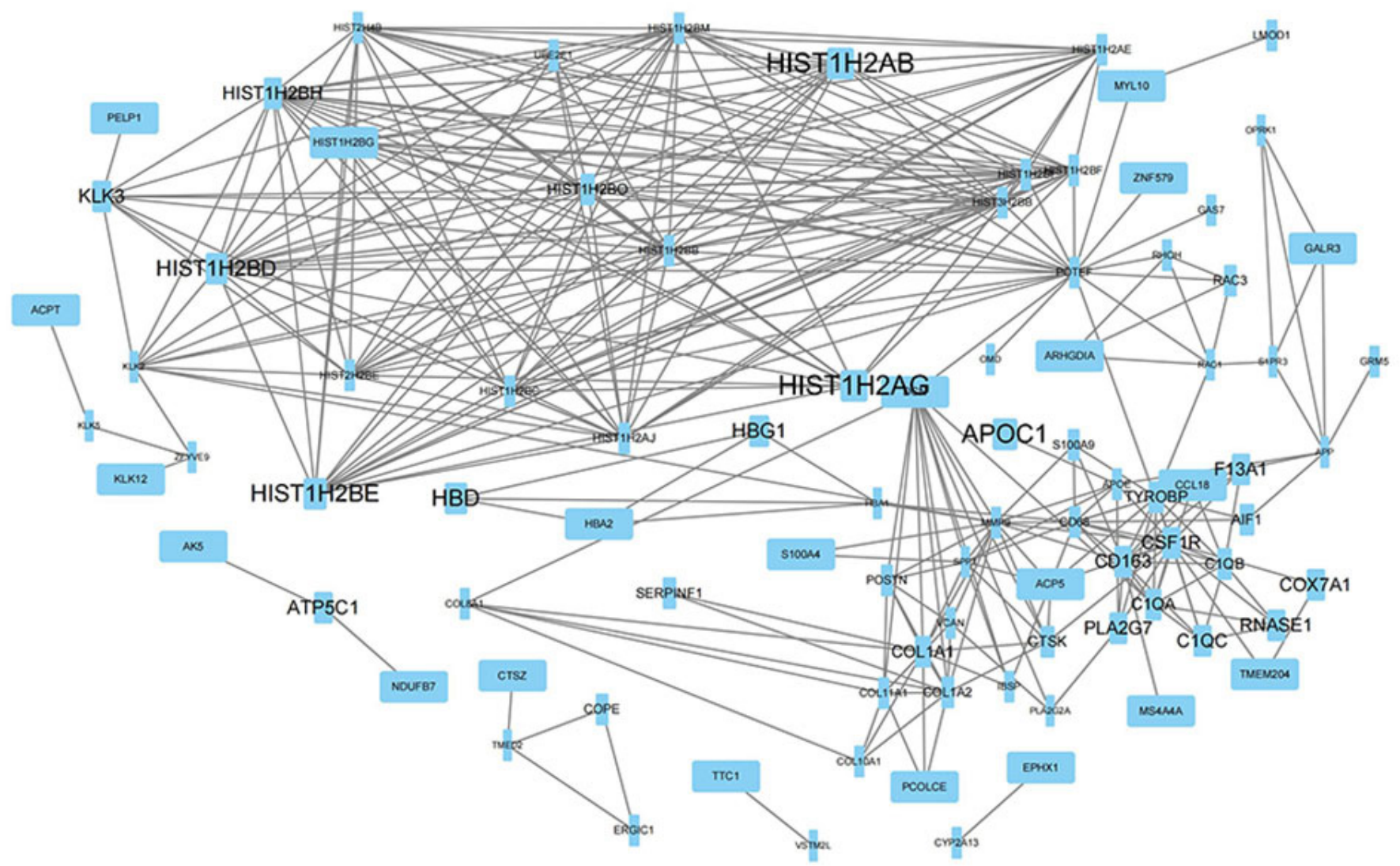

Figure 7. Differentially down-regulated key genes expressed in prostate cancer tissues. 
alpha -catenin) is decreased, and subsequently, promoting the invasion of cells and the swelling of the cells (Wang et al., 2011; Demirkol et al., 2020; Costa et al., 2020; Mostafa et al., 2021). ACP5 gene expressed tartaric acid resistant acid phosphatase $-5 \mathrm{a} / \mathrm{b}$, bone resorption osteoclasts, macrophages and dendritic cells can synthesize and secrete TRACP, osteoclasts only secrete $5 \mathrm{~b}$, macrophages and dendritic cells only secrete $5 \mathrm{~A}$. Therefore, TRACP-5a in blood circulation originates from macrophages and dendritic cells, while TRACP-5b originates from osteoclasts (Reithmeier, 2017). The above genes are important for the metastasis of tumor cells in prostate cancer. Increasing the expression of above genes in patients with bone metastasis will promote the proliferation and metastasis of tumor cells.

The human microsomal epoxide hydrolase (EPHX1) gene located on the autosomal 1q42.1, about $35.48 \mathrm{~kb}$, contains 9 exons and 8 introns, encodes microsomal epoxide hydrolase, and its third exon (exon 3) has T to C conversion, making EPHX1 113rd amino acids from histidine (Tyr) to arginine (His) and fourth exon 4 (exon 4) occurring A to G conversion makes EPHX1 139 th amino acid converted from histidine (His) to arginine (Arg), which can increase the susceptibility of urologic malignancies (Mittal \& Srivastava, 2007). The human tissue kallikrein family is a subfamily of serine protease, a substance with serine protease activity, which is expressed in steroid hormone tissue or hormone dependent tissues, such as the prostate, mammary gland, ovary, and testis. Overexpressing KLK12 is related to the malignancy of prostate cancer (Lose et al., 2013). Estrogen receptor co regulation factor proline proline, glutamate, leucine enriched protein 1 (Proline, -glutamic acid, -leucine rich protein 1, PELP1) increase the transformation potential of c-Src kinase, which can enhance estradiol mediated cell migration potential and anchor non- dependent growth. PELP1 is higher expressed in higher invasive prostate cancer (Yang et al., 2012). HIST1H2AC and HIST1H2BC or other histone genes are overexpressed in many kinds of tumor resistant cell lines, and overexpressing this gene can lead to bad prognosis (Mengual et al., 2006).

MS4A4A maintains the endocytosis of the mast cell receptor tyrosine kinase, which is important in the expression of tumor immunity (Sanyal et al., 2017; Kofler et al., 2012). TTC1 gene can promote the accumulation and phosphorylation of Ras, and activate the Ras signaling pathway. It may be directly or indirectly affect the activation of $\mathrm{T}$ cells and the releasing inflammatory mediators, leading to the onset or aggravation of immunological diseases such as psoriasis (Huang et al., 2016b). The up-regulated genes of bone metastases in prostate cancer are co enriched in the immunobiological processes related to systemic lupus erythematosus, allograft rejection, amyotrophic lateral sclerosis, and adhesion spots, which may be related to the poor prognosis caused by tumor immunity involved in bone metastasis. The content of GALR3 mRNA in the human frontal, temporal, striatum, medulla, cerebellum, and spinal cord is high in the human frontal, temporal, striatum, cerebellum and spinal cord, and is low in the hippocampus, the amygdala and the thalamus, and is associated with a large number of nervous system diseases (Wang et al., 1997). It may be related to the biological processes associated with Huntington's chorea, Artus's disease, Parkinson's disease, and neurotrophic factor signaling pathways.
The protein expressed by Zwint gene is crucial and indispensable for mitosis. The lack of checkpoint proteins is mainly located on the centromere of chromosomes, and varies with the cell cycle (Obuse et al., 2004). Zwint gene is associated with poor prognosis. DNA methylation is catalyzed by DNA methyltransferase. The family members of this gene include 4 members, DNM T1, DNM T2, DNM T3a, and DNM T3b. DNM T1 is the most important. It participates in the development and development of the tumor (Ying et al., 2018). RAD54B gene plays an important role in homologous recombination. It avoids the occurrence of gene mutation and may be related to the improvement of tumor prognosis (Dodge et al., 2005). The Zwint gene, DNM T gene and RAD54B gene affect the process of DNA repair. The expression of the three groups of genes in the lymph node metastasis may be more important than that in the bone metastasis (Wesoly et al., 2006). These genes can enhance adhesion and chemotaxis, immune correlation and malignant transformation of cancer cells. In patients with lymph node metastasis, the genes that prevent mutations in bone metastases are up-regulated. These changes affect the survival of the two. Our study and previous studies show that the mechanisms of bone and lymph node metastases are different. The systemic immune effect and the effect on the nervous system caused by bone metastasis in prostate cancer may play an important role, but there is a lack of research in this field. We need to further study it.

\section{Conclusion}

In conclusion, we used bioinformatics tools to analyze the gene expression changes of bone metastasis and lymph node metastasis in prostate cancer. From a large sample of survival data, we found that the prognosis of patients with lymph node metastasis is significantly better than that of patients with bone metastases. The main mechanism is that there is a significant difference in the pattern of gene expression in the tumor tissue of the patients with prostate cancer and lymph node metastasis, and the patients with prostate cancer have more adverse gene up-regulation than those with lymph node metastasis.

\section{Abbreviations}

DEGs: differentially expressed genes. OS: overall survival. PSA: prostate-specific antigen. PPI: Protein protein interaction. FC: Fold change. VEGF: vascular endothelial growth factor. MMP: matrix metalloproteinase. MIP-4: macrophage inflammatory protein-4. His: histidine. Arg: arginine.

\section{Ethical approval}

This article does not contain any studies with human participants or animals performed by any of the authors.

\section{Conflict of interest}

The authors report no conflicts of interest in this work.

\section{Authors contributions}

Jianfeng $\mathrm{Li}$ is responsible to the experimental studies, manuscript review. Shaoyu $\mathrm{Hu}$ is responsible to the clinical 
studies. Huafu $\mathrm{Li}$ is responsible to the manuscript preparation \& editing. Jie Jiang is responsible to the literature research, data analysis. Jianjun Wang is responsible to the guarantor of integrity of the entire study, study concepts \& design, data acquisition, statistical analysis. All authors are approved to this manuscript.

\section{References}

Arai, Y., Kanamaru, H., Yoshimura, K., Okubo, K., Kamoto, T., \& Yoshida, O. (1998). Incidence of lymph node metastasis and its impact on long-term prognosis in clinically localized prostate cancer. International Journal of Urology, 5(5), 459-465. http://dx.doi. org/10.1111/j.1442-2042.1998.tb00388.x. PMid:9781435.

Balthazar, C. F., Moura, N. A., Romualdo, G. R., Rocha, R. S., Pimentel, T. C., Esmerino, E. A., Freitas, M. Q., Santillo, A., Silva, M. C., Barbisan, L. F., Cruz, A. G., \& Albenzio, M. (2021). Synbiotic sheep milk ice cream reduces chemically induced mouse colon carcinogenesis. Journal of Dairy Science, 104(7), 7406-7414. http:// dx.doi.org/10.3168/jds.2020-19979. PMid:33934866.

Bi, X., Pohl, N. M., Qian, Z., Yang, G. R., Gou, Y., Guzman, G., KajdacsyBalla, A., Iozzo, R. V., \& Yang, W. (2012). Decorin-mediated inhibition of colorectal cancer growth and migration is associated with E-cadherin in vitro and in mice. Carcinogenesis, 33(2), 326-330. http://dx.doi.org/10.1093/carcin/bgr293. PMid:22159220.

Braadland, P. R., Ramberg, H., Grytli, H. H., \& Taskén, K. A. (2015). $\beta$-Adrenergic Receptor Signaling in Prostate Cancer. Frontiers in Oncology, 4, 375. http://dx.doi.org/10.3389/fonc.2014.00375. PMid:25629002.

Brawley, O. W. (2012). Prostate cancer epidemiology in the United States. World Journal of Urology, 30(2), 195-200. http://dx.doi. org/10.1007/s00345-012-0824-2. PMid:22476558.

Chen, J., Yao, Y., Gong, C., Yu, F., Su, S., Chen, J., Liu, B., Deng, H., Wang, F., Lin, L., Yao, H., Su, F., Anderson, K. S., Liu, Q., Ewen, M. E., Yao, X., \& Song, E. (2011). CCL18 from tumor-associated macrophages promotes breast cancer metastasis via PITPNM3. Cancer Cell, 19(4), 541-555. http://dx.doi.org/10.1016/j.ccr.2011.02.006. PMid:21481794.

Chen, Y., Lin, Y., Nie, P., Jiang, W., Liu, Y. Q., Yuan, R. Q., Li, M. Y., Zhao, S. J., Lin, H. X., Li, P. H., Zhang, J. X., Hu, Z. W., Xu, J., \& Zhu, X. S. (2017). Associations of prostate-specific antigen, prostate carcinoma tissue gleason score, and androgen receptor expression with bone metastasis in patients with prostate carcinoma. Medical Science Monitor, 23, 1768-1774. http://dx.doi.org/10.12659/MSM.900977. PMid:28400549.

Coleman, R. E. (1997). Skeletal complications of malignancy. Cancer, 80(Suppl. 8), 1588-1594. PMid:9362426.

Costa, G. A., Buccini, I. D. F., Arruda, A. L. A., Favaro, S. P., \& Moreno, S. E. (2020). Phytochemical profile, anti-inflammatory, antimutagenic and antioxidant properties of Acrocomia aculeata (Jacq.) Lodd. pulp oil. Food Science Technology, 40(4), 963-971. http://dx.doi. org/10.1590/fst.25319.

Demirkol, O., Gümüşay, Ö. A., \& Cerit, I. (2020). Effect of erythrosine and phloxine from xanthene food dyes on oxidative stress in Chinese hamster ovary cells. Food Science Technology, 40(4), 1009-1013. http://dx.doi.org/10.1590/fst.27819.

Dodge, J. E., Okano, M., Dick, F., Tsujimoto, N., Chen, T., Wang, S., Ueda, Y., Dyson, N., \& Li, E. (2005). Inactivation of Dnmt3b in mouse embryonic fibroblasts results in DNA hypomethylation, chromosomal instability, and spontaneous immortalization. The
Journal of Biological Chemistry, 280(18), 17986-17991. http://dx.doi. org/10.1074/jbc.M413246200. PMid:15757890.

Etzioni, R., Tsodikov, A., Mariotto, A., Szabo, A., Falcon, S., Wegelin, J., DiTommaso, D., Karnofski, K., Gulati, R., Penson, D. F., \& Feuer, E. (2008). Quantifying the role of PSA screening in the US prostate cancer mortality decline. Cancer Causes \& Control, 19(2), 175-181. http://dx.doi.org/10.1007/s10552-007-9083-8. PMid:18027095.

Franceschini, A., Szklarczyk, D., Frankild, S., Kuhn, M., Simonovic, M., Roth, A., Lin, J., Minguez, P., Bork, P., Von Mering, C., \& Jensen, L. J. (2013). STRING v9.1: protein-protein interaction networks, with increased coverage and integration. Nucleic Acids Research, 41(Database issue), D808-D815. PMid:23203871.

Ge, Y., Sealfon, S. C., \& Speed, T. P. (2009). Multiple testing and its applications to microarrays. Statistical Methods in Medical Research, 18(6), 543-563. http://dx.doi.org/10.1177/0962280209351899. PMid:20048384.

Hirakawa, S., Kodama, S., Kunstfeld, R., Kajiya, K., Brown, L. F., \& Detmar, M. (2005). VEGF-A induces tumor and sentinel lymph node lymphangiogenesis and promotes lymphatic metastasis. The Journal of Experimental Medicine, 201(7), 1089-1099. http://dx.doi. org/10.1084/jem.20041896. PMid:15809353.

Hu, J. X., Gao, J. Y., Zhao, Z. J., \& Yang, X. (2021). Response surface optimization of polysaccharide extraction from galla chinensis and determination of its antioxidant activity in vitro. Food Science Technology, 41(1), 188-196. http://dx.doi.org/10.1590/fst.38619.

Huang, C. Y., Hsu, H. C., Chang, C. H., Tseng, K. F., \& Fong, Y. C. (2006). Prostate cancer with bone metastases: a clinical profile. Mid-Taiwan Journal of Medicine, 11, 82-89.

Huang, K. C., Bégin, L. R., Palanisamy, N., Donnelly, B., \& Bismar, T. A. (2016a). SPINK1 expression in relation to PTEN and ERG in matched primary and lymph node metastatic prostate cancer: implications for biomarker development. Urologic Oncology, 34(5), 235.e1-235.e10. http://dx.doi.org/10.1016/j.urolonc.2015.11.015. PMid:26725250.

Huang, Y. B., Fan, X., \& Yang, C. J. (2016b). Interactions between IL-12B and TTC1 gene associate with psoriasis in Chinese Han population. Acta Universitatis Medicinalis Anhui, 51(7), 1039-1041.

Huber, W., Carey, V. J., Gentleman, R., Anders, S., Carlson, M., Carvalho, B. S., Bravo, H. C., Davis, S., Gatto, L., Girke, T., Gottardo, R., Hahne, F., Hansen, K. D., Irizarry, R. A., Lawrence, M., Love, M. I., MacDonald, J., Obenchain, V., Oles, A. K., Pages, H., Reyes, A., Shannon, P., Smyth, G. K., Tenenbaum, D., Waldron, L., \& Morgan, M. (2015). Orchestrating high-throughput genomic analysis with Bioconductor. Nature Methods, 12(2), 115-121. http://dx.doi. org/10.1038/nmeth.3252. PMid:25633503.

Kanehisa, M., Goto, S., Furumichi, M., Tanabe, M., \& Hirakawa, M. (2010). KEGG for representation and analysis of molecular networks involving diseases and drugs. Nucleic Acids Research, 38(Suppl. 1), 355-360. http://dx.doi.org/10.1093/nar/gkp896. PMid:19880382.

Khan, M. A., Amir, R. M., Ameer, K., Rakha, A., Faiz, F., Hayat, I., Nadeem, M., Ahmed, Z., Riaz, A., \& Ashraf, I. (2021). Characterization of oat bran B-glucan with special reference to efficacy study to elucidate its health claims for diabetic patients. Food Science Technology, 41(1), 105-112.

Kofler, J., Bissel, S., Wiley, C., Stauffer, M., \& Murdoch, G. (2012). Differential microglial expression of new Alzheimer's disease associated genes MS4A4A and MS4A6A. Alzheimer's \& Dementia, 8(4S, Part 7), P253-P253. http://dx.doi.org/10.1016/j.jalz.2012.05.675. 
Lee, C., Campbell, P., Whang, Y. M., Young, J. D., Elefteriou, F., \& Park, S. I. (2014). Targeting c-Met and VEGFR2 in the stromal compartment of prostate cancer bone metastasis. Cancer Research, 74, 1172.

Lose, F., Batra, J., O'Mara, T., Fahey, P., Marquart, L., Eeles, R. A., Easton, D. F., Al Olama, A. A., Kote-Jarai, Z., Guy, M., Muir, K., Lophatananon, A., Rahman, A. A., Neal, D. E., Hamdy, F. C., Donovan, J. L., Chambers, S., Gardiner, R. A., Aitken, J. F., Yaxley, J., Alexander, K., Clements, J. A., Spurdle, A. B., \& Kedda, M. A. (2013). Common variation in Kallikrein genes KLK5, KLK6, KLK12, and KLK13 and risk of prostate cancer and tumor aggressiveness. Urologic Oncology, 31(5), 635-643. http://dx.doi.org/10.1016/j. urolonc.2011.05.011. PMid:21741862.

Lu, Y., Yao, Z., \& Zhang, J. (2007). Prostate cancer bone metastasis, Interaction between tumor cells and bone microenviroument. Chinese Journal of Biochemistry and Molecular Biology, 23, 167-171.

Mazzucchelli, L. (2002). Protein S100A4: too long overlooked by pathologists? The American Journal of Pathology, 160(1), 7-13. http://dx.doi.org/10.1016/S0002-9440(10)64342-8. PMid:11786392.

Mengual, L., Burset, M., Ars, E., Ribal, M. J., Lozano, J. J., Minana, B., Sumoy, L., \& Alcaraz, A. (2006). Partially degraded RNA from bladder washing is a suitable sample for studying gene expression profiles in bladder cancer. European Urology, 50(6), 1347-1356. http://dx.doi.org/10.1016/j.eururo.2006.05.039. PMid:16815626.

Mittal, R. D., \& Srivastava, D. L. (2007). Cytochrome P4501A1 and microsomal epoxide hydrolase gene polymorphisms: gene-environment interaction and risk of prostate cancer. DNA and Cell Biology, 26(11), 791-798. http://dx.doi.org/10.1089/dna.2007.0630. PMid:17919073.

Mizutani, K., \& Pienta, K. J. (2008). Re: RANKL Inhibition Is an Effective Adjuvant for Docetaxel in a Prostate Cancer Bone Metastasis Model. European Urology, 54(3), 688. http://dx.doi.org/10.1016/j. eururo.2008.06.026. PMid:18792431.

Morrissey, C., True, L. D., Roudier, M. P., Coleman, I. M., Hawley, S., Nelson, P. S., Coleman, R., Wang, Y. C., Corey, E., Lange, P. H., Higano, C. S., \& Vessella, R. L. (2008). Differential expression of angiogenesis associated genes in prostate cancer bone, liver and lymph node metastases. Clinical \& Experimental Metastasis, 25(4), 377388. http://dx.doi.org/10.1007/s10585-007-9116-4. PMid:17972146.

Mostafa, H. S., Ali, M. R., \& Mohamed, R. M. (2021). Production of a novel probiotic date juice with anti-proliferative activity against Hep-2 cancer cells. Food Science Technology, 41(Suppl. 1), 105-115. http://dx.doi.org/10.1590/fst.09920.

Moul, J. W., Wu, H., Sun, L., McLeod, D. G., Amling, C., Lance, R., Kusuda, L., Donahue, T., Foley, J., Chung, A., Sexton, W., Soderdahl, D., \& Rich, N. M. (2002). Epidemiology of radical prostatectomy for localized prostate cancer in the era of prostate-specific antigen: an overview of the Department of Defense Center for Prostate Disease Research national database. Surgery, 132(2), 213-219. http://dx.doi. org/10.1067/msy.2002.125315. PMid:12219014.

Mundy, G. R. (2002). Metastasis to bone: causes, consequences and therapeutic opportunities. Nature Reviews. Cancer, 2(8), 584-593. http://dx.doi.org/10.1038/nrc867. PMid:12154351.

Obuse, C., Iwasaki, O., Kiyomitsu, T., Goshima, G., Toyoda, Y., \& Yanagida, M. (2004). A conserved Mis12 centromere complex is linked to heterochromatic HP1 and outer kinetochore protein Zwint-1. Nature Cell Biology, 6(11), 1135-1141. http://dx.doi.org/10.1038/ ncb1187. PMid:15502821.

Ohta, S., Wada, H., Nakazaki, T., Maeda, Y., Nobori, T., Shiku, H., Nakamura, S., Nagakawa, O., Furuya, Y., \& Fuse, H. (2002). Expression of tissue factor is associated with clinical features and angiogenesis in prostate cancer. Anticancer Research, 22(5), 29912996. PMid:12530031.

Pernar, C. H., Ebot, E. M., Wilson, K. M., \& Mucci, L. A. (2018). The Epidemiology of Prostate Cancer. Cold Spring Harbor Perspectives in Medicine, 8(12), a030361. http://dx.doi.org/10.1101/cshperspect. a030361. PMid:29311132.

Reithmeier, A. (2017). Tartrate-resistant acid phosphatase/ACP5 as a driver of cancer: dissection of its oncogenic mechanisms and identification of small molecule inhibitors. Stockholm: Karolinska Institutet.

Roodman, G. D. (2004). Mechanisms of bone metastasis. The New England Journal of Medicine, 350(16), 1655-1664. PMid:15084698.

Roudier, M. P., Winters, B. R., Coleman, I., Lam, H. M., Zhang, X., Coleman, R., Chéry, L., True, L. D., Higano, C. S., Montgomery, B., Lange, P. H., Snyder, L. A., Srivastava, S., Corey, E., Vessella, R. L., Nelson, P. S., Üren, A., \& Morrissey, C. (2016). Characterizing the molecular features of ERG-positive tumors in primary and castration resistant prostate cancer. Prostate, 76, 810-822.

Sanyal, R., Polyak, M. J., Zuccolo, J., Puri, M., Deng, L., Roberts, L., Zuba, A., Storek, J., Luider, J. M., Sundberg, E. M., Mansoor, A., Baigorri, E., Chu, M. P., Belch, A. R., Pilarski, L. M., \& Deans, J. P. (2017). MS4A4A: a novel cell surface marker for M2 macrophages and plasma cells. Immunology and Cell Biology, 95(7), 611-619. http://dx.doi.org/10.1038/icb.2017.18. PMid:28303902.

Shannon, P., Markiel, A., Ozier, O., Baliga, N. S., Wang, J. T., Ramage, D., Amin, N., Schwikowski, B., \& Ideker, T. (2003). Cytoscape: a software environment for integrated models of biomolecular interaction networks. Genome Research, 13(11), 2498-2504. http:// dx.doi.org/10.1101/gr.1239303. PMid:14597658.

Shida, A., Fujioka, S., Takahashi, N., Aoki, H., Okamoto, T., Mitsumori, N., Omura, N., \& Yanaga, K. (2013). Reduced expression of Rho GDP dissociation inhibitor $2 \mathrm{mRNA}$ is associated with lymph node metastasis in gastric carcinoma. Oncology Letters, 6(2), 463-467. http://dx.doi.org/10.3892/ol.2013.1379. PMid:24137348.

Stacker, S. A., Caesar, C., Baldwin, M. E., Thornton, G. E., Williams, R. A., Prevo, R., Jackson, D. G., Nishikawa, S., Kubo, H., \& Achen, M. G. (2001). VEGF-D promotes the metastatic spread of tumor cells via the lymphatics. Nature Medicine, 7(2), 186-191. http://dx.doi. org/10.1038/84635. PMid:11175849.

Swanson, G. P., Thompson, I. M., \& Basler, J. (2006). Current status of lymph node-positive prostate cancer: Incidence and predictors of outcome. Cancer, 107(3), 439-450. http://dx.doi.org/10.1002/ cncr.22034. PMid:16795064.

Tian, T. V., Tomavo, N., Huot, L., Flourens, A., Bonnelye, E., Flajollet, S., Hot, D., Leroy, X., Launoit, Y., \& Duterque-Coquillaud, M. (2014). Identification of novel TMPRSS2:ERG mechanisms in prostate cancer metastasis: involvement of MMP9 and PLXNA2. Oncogene, 33(17), 2204-2214. http://dx.doi.org/10.1038/onc.2013.176. PMid:23708657.

Torre, L. A., Bray, F., Siegel, R. L., Ferlay, J., Lortet-Tieulent, J., \& Jemal, A. (2015). Global cancer statistics. CA: a Cancer Journal for Clinicians, 65(2), 87-108. http://dx.doi.org/10.3322/caac.21262. PMid:25651787.

Wang, J., Chen, L., Li, Y., \& Guan, X. Y. (2011). Overexpression of Cathepsin $\mathrm{Z}$ contributes to tumor metastasis by inducing epithelialmesenchymal transition in hepatocellular carcinoma. PLoS One, 6(9), e24967. http://dx.doi.org/10.1371/journal.pone.0024967. PMid:21966391.

Wang, S., He, C., Hashemi, T., \& Bayne, M. (1997). Cloning and expressional characterization of a novel galanin receptor. Identification of different pharmacophores within galanin for the three galanin 
receptor subtypes. The Journal of Biological Chemistry, 272(51), 3194931952. http://dx.doi.org/10.1074/jbc.272.51.31949. PMid:9405385.

Wesoly, J., Agarwal, S., Sigurdsson, S., Bussen, W., Van Komen, S., Qin, J., Van Steeg, H., Van Benthem, J., Wassenaar, E., Baarends, W. M., Ghazvini, M., Tafel, A. A., Heath, H., Galjart, N., Essers, J., Grootegoed, J. A., Arnheim, N., Bezzubova, O., Buerstedde, J. M., Sung, P., \& Kanaar, R. (2006). Differential contributions of mammalian Rad54 paralogs to recombination, DNA damage repair, and meiosis. Molecular and Cellular Biology, 26(3), 976-989. http:// dx.doi.org/10.1128/MCB.26.3.976-989.2006. PMid:16428451.
Yang, L., Ravindranathan, P., Ramanan, M., Kapur, P., Hammes, S. R., Hsieh, J. T., \& Raj, G. V. (2012). Central role for PELP1 in nonandrogenic activation of the androgen receptor in prostate cancer. Molecular Endocrinology, 26(4), 550-561. http://dx.doi. org/10.1210/me.2011-1101. PMid:22403175.

Ying, H., Xu, Z., Chen, M., Zhou, S., Liang, X., \& Cai, X. (2018). Overexpression of Zwint predicts poor prognosis and promotes the proliferation of hepatocellular carcinoma by regulating cellcycle-related proteins. OncoTargets and Therapy, 11, 689-702. http:// dx.doi.org/10.2147/OTT.S152138. PMid:29440916. 